\title{
Assessment of Trans Fatty Acid Content in Widely Consumed Snacks by Gas Chromatography in a Developing Country
}

\author{
Smita Karn, Ransi Ann Abraham, Lakshmy Ramakrishnan*
}

Department of Cardiac Biochemistry, All India Institute of Medical Sciences, New Delhi, India.

Email: Smitakarn@gmail.com, ransijob@gmail.com, ${ }^{*}$ Lakshmy_ram@yahoo.com

Received August $19^{\text {th }}, 2013$; revised September 19 ${ }^{\text {th }}, 2013$; accepted September $26^{\text {th }}, 2013$

Copyright (C) 2013 Smita Karn et al. This is an open access article distributed under the Creative Commons Attribution License, which permits unrestricted use, distribution, and reproduction in any medium, provided the original work is properly cited. In accordance of the Creative Commons Attribution License all Copyrights (C) 2013 are reserved for SCIRP and the owner of the intellectual property Smita Karn et al. All Copyright (C) 2013 are guarded by law and by SCIRP as a guardian.

\begin{abstract}
Trans fatty acids have adverse effects on health, so knowledge of their contents in foods would enable people to make informed food choices. TFA levels when not available in food composition tables make it difficult to estimate dietary intake. With the aim to analyze and identify the actual amount of trans fatty acid present in selected Indian fast food items, triplicate samples of six commonly consumed snacks as well as the oil used for preparing the same were collected from three different places. The separation of fatty acid was done using gas chromatography. Trans fatty acid isomers of oleic acid, linoleic acid and linolenic acid were identified in all food items. The predominant trans fatty acid present in all the food items was elaidic acid (18:1t9). The total trans fatty acids in different food items ranged from almost negligible to as high as $14.58 \mathrm{~g} / 100 \mathrm{~g}$ food. Different amount of TFA was found in same food category sourced from different outlets which is a challenge in making regulations aimed at TFA reduction so as to decrease health risk.
\end{abstract}

Keywords: Trans Fatty Acid; Gas Chromatography; Snack; Health Risk

\section{Introduction}

There are growing concerns for potential health effects of trans fatty acid (TFA) particularly those that are derived from partially hydrogenated vegetable oils (PHVO). PHVO offers an attractive option for food industry because of their long shelf life, their stability during deepfrying and their semisolidity, which enhances the palatability of baked goods and sweets [1]. PHVO contributes to TFA intake, which can be up to $40 \%$ [2,3]. In India, fast foods/street foods are becoming part of our lifestyle and 400,000 tonnes of snacks are consumed every year. The Indian National Sample Survey Organization, India shows that consumption of beverages, biscuits, processed foods, salted snacks, prepared sweets and other purchased foods ranged from $100-427 \mathrm{gm} /$ capita/day. Major dietary sources of TFA in India are deep fried fast foods such as samosas, baked products, packed snack foods, margarines and crackers [4,5]. The deep fried foods, unlike packaged snacks which display their nutri-

${ }^{*}$ Corresponding author. tive value on packets, are commonly sold by vendors and difficult to be brought under regulations. However efforts can be made to reduce their trans fatty acid content based on actual data obtained by direct measurement.

The Centre for Sciences and Environment study has reported TFA levels 5 to 12 times higher in the oils consumed in India as compared to the world standard for trans fats in oil [3]. Most of the fatty acid enters our diet through oil used in household cooking, restaurant, as well as the deep fried fast food like samosa, pakora etc. which are consumed widely. High TFA content $(1.9 \%$ $53 \%$ ) has been reported in Indian sweets and savories/snacks by Agrawal et al. [5]. The authors derived the amount of TFA by calculating nutritive values of raw material such as oil and fats used in recipes, which is secondary in nature. The usual methods for dietary measures of TFA are food frequency questionnaire, diet histories and food records which have inherent shortcomings. The increasing complexity of the food supply and the availability of a wide range of manufactured and 
processed foods, coupled with variations in the fats and oils used by the food industry make the compilation of the fatty acid composition of foods difficult [6]. Also during cooking many changes occur that can potentially influence TFA content in food. Lack of an accurate and comprehensive database on the trans fatty acid composition of food particular to a region is often a hurdle in nutritional studies. Databases on trans fatty acids whenever available are scarce, scattered and outdated. Hence a pilot study was undertaken to assess the trans fatty acid content, by gas chromatography, of selected commonly consumed savories/sweets in India.

\section{Material and Methods}

\subsection{Sample Collection}

Based on a survey conducted in 2002-2003 among industrial population of Delhi [7] six commonly consumed snacks, Balushahi [flour, ghee or PHVO, yogurt in sugar syrup], Laddu [balls of flour, sugar and Ghee or PHVO], Mathari [deep fried flour with shortening], Bhatura [fried flour with shortening], Bread Pakora [Fried chickpea flour and vegetables with bread] and Samosa [deep-fried pastry containing vegetable or meat] and widely used bakery items such as cake, biscuits and bread, known to be potentially high in TFA were identified for analysis. Triplicate samples of food were purchased from three different places i.e. 1) branded sweet shops, 2) local sweet shop and 3) roadside vendors on a random basis for analysis of their TFA content. Oil samples, used in preparation of fried items such as Balushahi, Mathari, Bhatura, Bread Pakora, and Samosa were also collected at the time of purchasing the food samples and were processed and analyzed in triplicate. All the food samples were weighed and stored at $-70^{\circ} \mathrm{C}$ temperature until further analysis.

\subsection{Fatty Acid Estimation}

Fat was extracted from food items using the AOAC Official Method SM 996.06, AOAC Official Method 969.33 [8]. An accurately weighed $1 \mathrm{~g}$ homogenized food sample was mixed with $2.0 \mathrm{ml}$ ethanol, the entire product was dispersed in $10.0 \mathrm{ml}$ of $8.3 \mathrm{M} \mathrm{HCl} .2 \mathrm{ml}$ of triundecanoic acid (5 $\mathrm{mg}$ triundecanoic acid in $1 \mathrm{ml} \mathrm{CHCl}_{3}$ ) was used as the internal standard. The tubes were incubated for 60 minutes at $80^{\circ} \mathrm{C}$ in a water bath with intermittent mixing every $10 \mathrm{~min}$. After digestion, the test tubes were allowed to cool at room temperature. $2 \mathrm{ml}$ ethanol was added through the sides of the tube, mixed for 1 minute followed by $25 \mathrm{ml}$ diethyl ether and again mixed for 5 minutes. $25 \mathrm{ml}$ petroleum ether was added, mixed for 5 minutes and allowed to remain for 1 hour until the upper ether phase becomes clear. The upper phase was trans- ferred into $150 \mathrm{ml}$ beaker and dried slowly under Nitrogen stream. The extracted fat was weighed and transferred into a glass vial with $3 \mathrm{ml}$ chloroform and $3 \mathrm{ml}$ diethyl ether and dried again. $2 \mathrm{ml}$ of 7\% Boron tri fluoride $\left(\mathrm{BF}_{3}\right)$, methylating agent, and $1 \mathrm{ml}$ toluene was then added with intermittent mixing to the extracted fat and heated at $100^{\circ} \mathrm{C}$ for 45 minutes to convert the fat into fatty acid methyl esters (FAME). After methylation, $1 \mathrm{~g}$ sodium sulfate solution was added to remove moisture content. Esters were extracted with $1 \mathrm{ml}$ hexane transferred into $2 \mathrm{ml}$ vial (Teflon capped) and loaded on gas chromatography (GC) after appropriate dilutions.

Fatty acid methyl ester of the oil samples was prepared according to AOAC Official Method 969.33 with modification [9]. Accurately weighed $200 \mathrm{mg}$ oil sample along with $4 \mathrm{ml}$ of Methanolic Sodium Hydroxide $(0.5 \mathrm{M})$ were placed at $100^{\circ} \mathrm{C}$ temperature (in oven or water bath) and heated for 2 minutes to saponify the lipid (a few glass beads was added to prevent bumping while heating). The tubes were then cooled and $5 \mathrm{ml}$ boron trifluoride $\left(\mathrm{BF}_{3}\right)$ a methylating agent was added. To this tube, $2 \mathrm{~mL}$ hexane and $15 \mathrm{ml}$ saturated $\mathrm{NaCl}$ solution was added followed by vigorous mixing for 15 seconds. The upper layer was transferred into $2 \mathrm{ml}$ sample vial (Teflon capped) and loaded on GC with appropriate dilution.

\subsection{Gas Chromatographic Analysis}

The fatty acid methyl esters were run on gas chromatography (GC) which was equipped with a flame-ionization detector. Fused silica capillary cis/trans column SP 2560, $100 \mathrm{~m} \times 250 \mu \mathrm{m}$ internal diameters $\times 0.20 \mu \mathrm{m}$ film was used (Supelco, Belefonte, Pennsylvania). The following temperature programme was used for optimal separation of fatty acids including trans fatty acids: initial oven temperature was $140^{\circ} \mathrm{C}$, hold time was for 5 minutes; ramp $1^{\circ} \mathrm{C} / \mathrm{min}$; final temperature was $250^{\circ} \mathrm{C}$; hold time was 25 minutes, and total run time was 120 minutes. Injector port was $225^{\circ} \mathrm{C}$; Detector port was $260^{\circ} \mathrm{C}$; and the gas rates used were $0.3 \mathrm{ml} / \mathrm{min}$ carrier gas (Nitrogen), 15 $\mathrm{ml} / \mathrm{min}$ make up gas (Nitrogen) and 35 and $350 \mathrm{ml} / \mathrm{min}$ flame gases hydrogen and air, respectively. A split ratio of $1: 10$ and an injection volume of $1 \mu$ l were used. The fatty acid composition was determined by comparing their retention times with those of known standards (fatty acid methyl esters from SUPELCO). Each peak was quantified by calculating the area under the peak using software from AIMIL (Nucon Technologies). The concentration of individual fatty acid was expressed as percentage of total area under the peak. A total of 22 fatty acids were identified in the samples and grouped into saturated fatty acid (SFA), monounsaturated fatty acid (MUFA), polyunsaturated fatty acid (PUFA) and trans fatty acid (TFA). The SFA included C14:0, C16:0 and 
C18:0, the MUFA included C16:1, C18:1 and C22:1 and the PUFA comprised of three fatty acids: C18:2, C18:3 n-6 and C18:3 n-3. The TFA included C16:1t, C18:1t9, C18:2tt, C18:2tc, C18:2ct, C18:3ttt, C18:3ttc, C18:3tct, C18:3ctt, C18:3cct, C18:3ctc, C18:3tcc and C22:1t. Trans fatty acid was expressed as $\mathrm{g} / 100 \mathrm{~g}$ food.

\section{Results}

A total of 27 food samples were collected and the samples were analyzed in triplicate. Average recovery of internal standard, triundecanoic acid (C11:0), added to the food items before extraction was $89 \%$ (Range: $86 \%$ to $94 \%$ ). The median and interquartile range of fatty acid for the food items is given in Tables $\mathbf{1}$ and $\mathbf{2}$ and that for oil is given in Table 3. Figure 1 and 2 show the representative chromatogram of one snack (Balushahi) and the corresponding oil used for its preparation. The SFA,
PUFA and MUFA content in the oil showed wide variation. Highest amount of TFA content was found in Mathari $(7.33 \mathrm{~g} / 100 \mathrm{~g}$, range $4.88 \mathrm{~g} / 100 \mathrm{~g}$ to $13.56 / 100 \mathrm{~g}$ ) and the level of TFA in the oil used for frying Mathari was $6 \mathrm{~g} / 100 \mathrm{~g}$ (range: $3.4 \mathrm{~g} / 100 \mathrm{~g}$ to $7.2 \mathrm{~g} / 100 \mathrm{~g}$ ) whereas lowest TFA was observed in samosa $0.25 \mathrm{~g} / 100 \mathrm{~g}(0.21$ $\mathrm{g} / 100 \mathrm{~g}-3.65 \mathrm{~g} / 100 \mathrm{~g}$ ) and their levels in oil ranged from $1.88 \mathrm{~g} / 100 \mathrm{~g}$ to $9.12 \mathrm{~g} / 100 \mathrm{~g}$.

\section{Discussion}

The total trans fatty acids in different food ranged from almost negligible to levels as high as $14.58 \mathrm{~g} / 100 \mathrm{~g}$ food, while the TFA levels in oil samples ranged from 1.64 $\mathrm{g} / 100 \mathrm{~g}$ to $9.47 \mathrm{~g} / 100 \mathrm{~g}$. The predominant trans fatty acid present in the food items was elaidic acid (18:1t9). Different amount of TFA was found in same food item sourced from different outlets such as branded sweet

Table 1. Fatty acid composition of selected food.

\begin{tabular}{|c|c|c|c|c|}
\hline Snacks & TFA $\%$ of fat & SFA $\%$ of fat & MUFA $\%$ of fat & PUFA $\%$ of fat \\
\hline Laddu & $22.53(18.2-26.6)$ & $67.71(52.6-74.7)$ & $5.9(5.6-8.3)$ & $3.84(1.99-4.61)$ \\
\hline Mathari & $13.54(11-21.23)$ & $67.7(57.4-71.8)$ & $31.05(29.5-31.9)$ & $4.7(2.62-9.6)$ \\
\hline Bhatura & $8(7.58-22.76)$ & $54.5(47.5-63)$ & $22(8.65-27.95)$ & $11.6(2.87-14.6)$ \\
\hline Bread Pakora & $2.19(0.7-2.55)$ & $70.7(47-87)$ & $4.4(3.6-6.86)$ & $20.9(1.53-46.4)$ \\
\hline Samosa & $1.23(1.2-18.1)$ & $55.6(6-65.5)$ & $18.4(8.8-30.4)$ & $11.2(1.85-45.3)$ \\
\hline Cake & $13.52(6.25-20.1)$ & $80.75(75.3-84.6)$ & $5.25(2.5-10.8)$ & $0.12(0.02-0.17)$ \\
\hline Biscuit & $13.68(12.39-13.9)$ & $85.8(83.6-87.1)$ & $0.05(0.01-0.59)$ & $0.1(0.04-0.48)$ \\
\hline
\end{tabular}

Values are median (interquartile range), TFA-Trans fatty acid: SFA: Saturated fatty acid, MUFA: Monounsaturated fatty acid: PUFA: polyunsaturated fatty acid.

Table 2. Trans fatty acid levels in food.

\begin{tabular}{|c|c|c|c|}
\hline Snacks & Total fat $\mathrm{g} / 100 \mathrm{~g}$ food & TFA $\%$ of fat & TFA g/100g food \\
\hline Laddu & $31(28.85-33.4)$ & $22.53(18.2-26.6)$ & $6.75(6.2-7.3)$ \\
\hline Mathari & $48.8(41.4-51.4)$ & $13.54(11-21.23)$ & $7.33(4.88-13.56)$ \\
\hline Bhatura & $31(30-36.85)$ & $8(7.58-22.76)$ & $2.5(2.25-9.1)$ \\
\hline Bread Pakora & $25(24-25)$ & $2.19(0.7-2.55)$ & $1.05(0.36-2.4)$ \\
\hline Samosa & $19.4(18.05-19.7)$ & $1.23(1.2-18.1)$ & $0.25(0.21-3.65)$ \\
\hline Cake & $20(20-20)$ & $13.52(6.25-20.1)$ & $2.7(1.25-4.12)$ \\
\hline Biscuit & $18(18-20.5)$ & $13.68(12.39-13.9)$ & $2.46(2.23-2.85)$ \\
\hline
\end{tabular}

Values are median (interquartile range). 
1284 Assessment of Trans Fatty Acid Content in Widely Consumed Snacks by Gas Chromatography in a Developing Country

Table 3. Fatty acid composition of oil used in preparation of foods.

\begin{tabular}{ccccc}
\hline Sample & SFA & MUFA & PUFA & TFA g/100gm \\
\hline Balushahi (oil) & $18(14-85)$ & $10.4(4.47-25.2)$ & $59.6(2.9-61.8)$ & $0.34(0.27-6)$ \\
Mathari (oil) & $60.5(40.6-68.6)$ & $21.7(9.35-38.65)$ & $16.4(11.53-17.24)$ & $6(3.4-7.2)$ \\
Bhatura (oil) & $52.9(43.5-61.6)$ & $25.9(13-30)$ & $8.44(1.38-14.28)$ & $8.35(4-23.8)$ \\
Bread Pakora (oil) & $75.9(74.1-77)$ & $5.35(4.9-5.8)$ & $14.85(1.76-18.7)$ & $1.79(1.07-15.3)$ \\
Samosa (oil) & $47.4(6.42-51.5)$ & $41.6(27.5-46.15)$ & $10.87(9.9-41.7)$ & $1.68(1.18-9.12)$ \\
\hline
\end{tabular}

Values are median (interquartile range), SFA-Saturated fatty acid: MUFA-Monounsaturated fatty acid, PUFA-polyunsaturated fatty acid: TFA-Trans fatty acid.

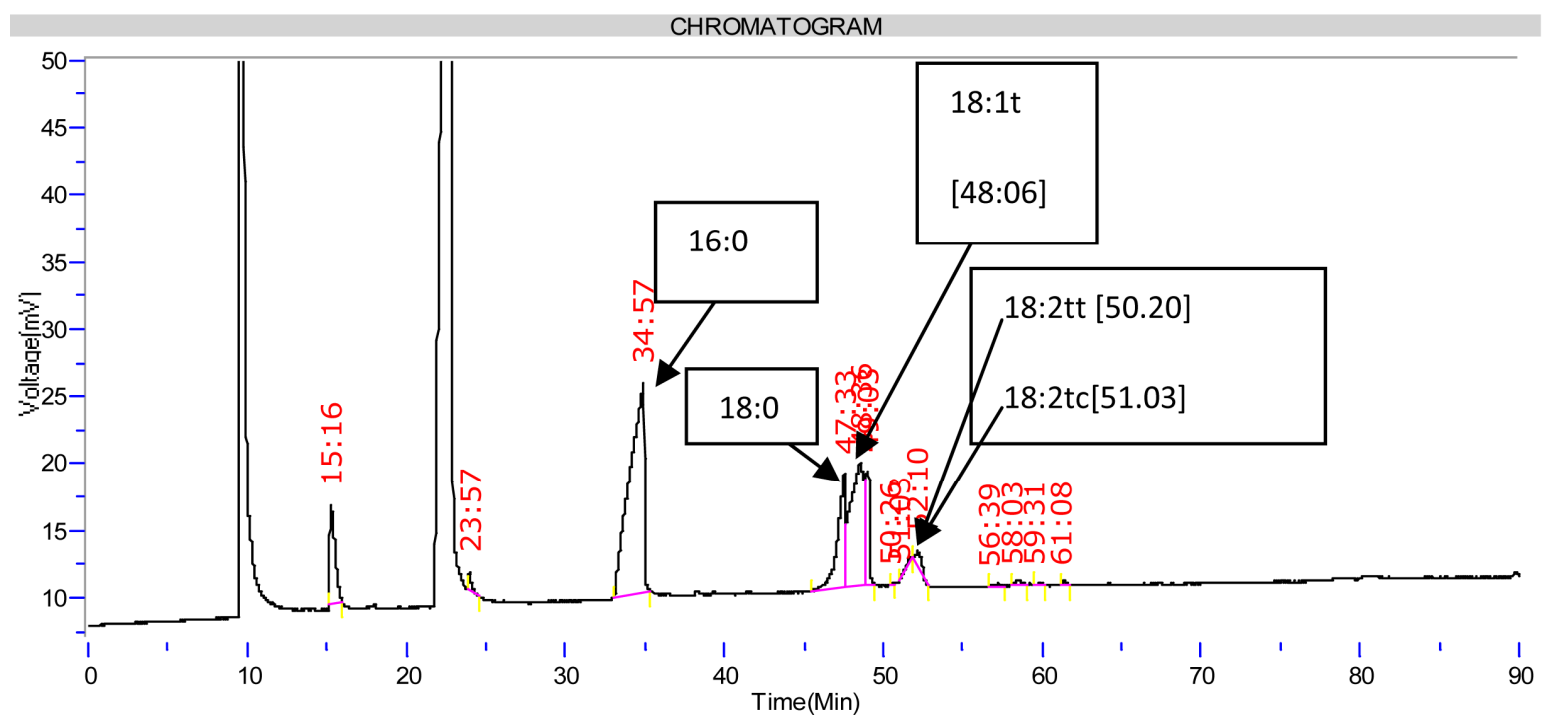

Figure 1. Representative chromatogram of the snack (Balushahi).

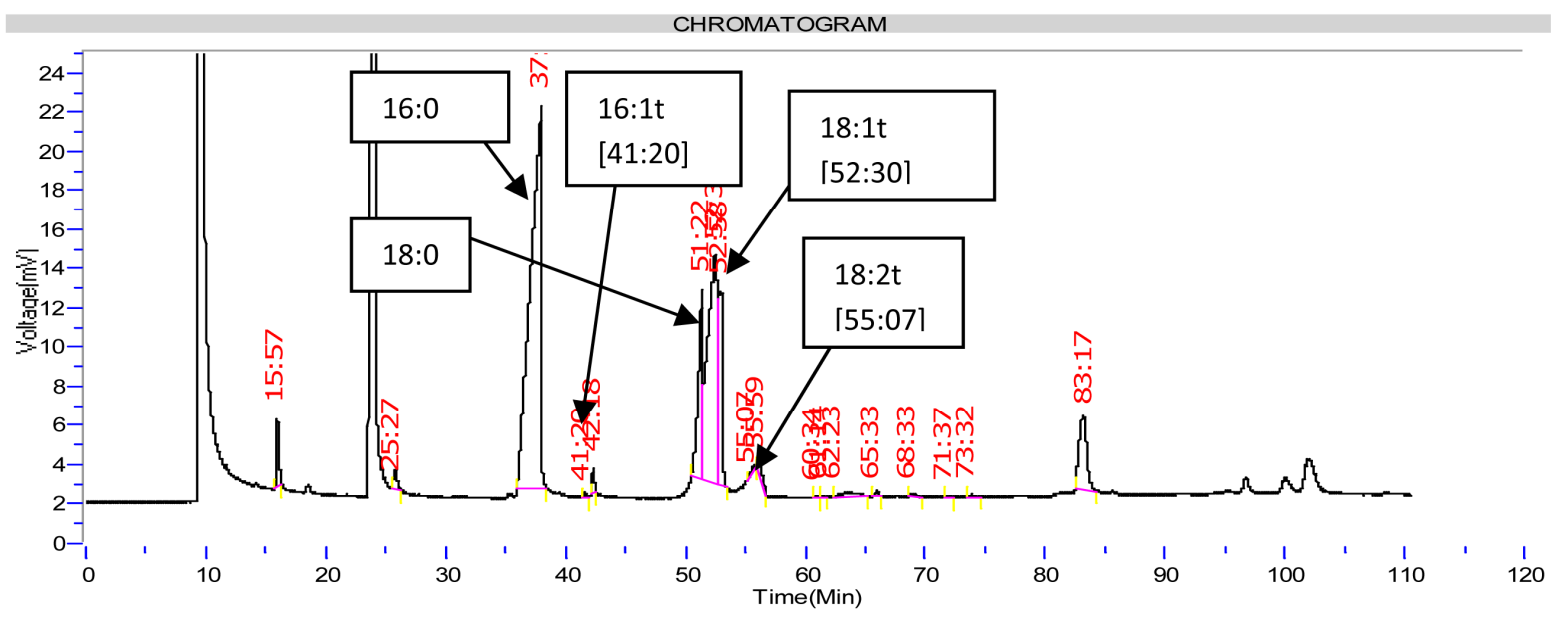

Figure 2. Representaive chromatogram of oil (used in frying Balushahi).

shop, local sweet shop and roadside vendors. A reason for this variability is that products often contain a blend of partially hydrogenated vegetable oils (PHVO) of different sources such as soybean, canola, palm oil, corn and sunflower oil. The proportions of hydrogenated and non-hydrogenated oils in these foods are varied to obtain the desired physical properties. In studies done in Australia and Canada high level of TFA was found in over $10 \%$ of food items analyzed and the authors also found great variability in TFA content in crackers, doughnuts and chocolate wafer biscuits. Earlier studies have also reported varied TFA level within similar food items due 
to type of oil used in preparation [9-16]. These variability reflects the difficulty in assessing TFA intake in a population especially by dietary methods which depend on food composition tables. Developing food composition tables for every region is time consuming and economically non viable exercise especially in developing countries.

The TFA values observed in this study was marginally lower than the earlier reported values. Agrawal et al. [5] has reported TFA value for Laddu as $10.2 \mathrm{~g} / 100 \mathrm{~g}$ food, $7.6 \mathrm{~g}$ for Balushahi, $16.3 \mathrm{~g}$ and $3.3 \mathrm{~g}$ for Mathari and Samosa respectively. This difference may be because the TFA values were generated as secondary data, which is calculated based on the amount of PHVO/oil used in preparation, whereas in our study TFA was estimated by GC which quantitates actual levels of TFA in the food. Recently Johnson et al. [17] reported high trans fatty acid content in Indian junk foods where they have included packaged snacks in the study. They however did not analyzed trans fatty acid in street foods and snacks. Fatty acid composition of food and their oils used for frying was different in our study. This may be because of difference in fat and oil used in shortening and frying individual food item. The majority of the outlets appeared to have used non-hydrogenated vegetable oils for frying. The street food and snacks vendors comprise of an unorganized sector who are mostly unaware of the regulations to check trans fatty acid content in food. The public at large do not have an opportunity to make informed choices which helps in reducing TFA intake as well as decrease health risk. The range of snacks and savouries available in the market are wide and analyzing all of them for trans fatty acid content is beyond the scope of this study. Prevention of Food Adulteration Act of India, 1955 require that the foods in which hydrogenated vegetable fats or bakery shortening is used shall declare on the label that "Hydrogenated vegetable fats or bakery shortening used-contains trans fats" and a health claim of "trans fat free" may be made where the trans fat is less than $0.2 \mathrm{~g}$ per serving of food. The oil and fats subcommittee of the Ministry of Health and Family Welfare (MoHFW) in March 2009, had agreed on a 10 percent limit on trans fats in vanaspati ghee sold in India. Members of this sub-committee also agreed that the trans fat levels should be brought down to five percent in three years.

The SFA content found in the food samples and their oils in this study was high when compared to values reported by Centre for Science and Environment in oils used in India [17] The CSE has reported fatty acid profile for fresh oil. Reheating of oils increases SFA and may be the reason for higher SFA in food samples in the present study. Alireza et al. [18] has reported that Palmitic (16:0) acid content increase with the prolonged frying where as linoleic acid (18:2) and linolenic acid (18:3) fatty acid content was decreased. Similarly Soliman et al. [19] found the increase in the content of palmitic, stearic and total saturated fatty acid with increased frying time. Repeated reuse of oil for frying introduces components in food increasing health risk.

\section{Conclusion}

Unlike the previously reported studies where the level of trans fatty acids content of foods was derived as secondary data from the oil used, we have analyzed and documented the actual total TFA levels in some snacks widely consumed by the population. Since the adverse affects of trans fatty acids have been conclusively shown in many studies, calculating and analyzing the actual amount of trans fat in foods in every region are essential to assess the actual risk that consumption of these foods carries rather than relying on the food composition tables. Such studies can help to analyse the quality of oil being used in public eateries and open up the possibility of discussion on how to reduce TFA intake.

\section{Acknowledgements}

This research was funded by the senior research fellow grant of Indian Council of Medical Research. The author declares that the work described has not been published previously. The authors' contributions to the study were as follows: SK carried out the work and wrote the manuscript, RA provided intellectual input for carrying out the experiment and writing the manuscript, LR helped in study design, gave statistical inputs and edited the manuscript. All authors read and approved the final manuscript. The authors declare that they have no competing interest.

\section{REFERENCES}

[1] G. V. Mann, "Metabolic Consequences of Dietary Trans Fatty Acids," Lancet, Vol. 343, No. 8908, 1994, pp. 1268-1271. http://dx.doi.org/10.1016/S0140-6736(94)92157-1

[2] K. Sambaiah and B. R. Lokesh, "Nutritional Properties of Trans Fatty Acids," Indian Journal of Biochemistry \& Biophysics, Vol. 36, No. 4, 1999, pp. 211-220.

[3] S. Johnson and N. Saikia, "Fatty Acids Profile of Edible Oils and Fat in India," Centre for Science and Environment, New Delhi, 2008, p. 9.

[4] V. S. Sadasivam, "Globalization of Food System in Developing Countries: Impact on Food Security and Nutrition," Food Agriculture Organization, Geneva, 2004, pp. 215-230.

[5] A. Agrawal, R. Gupta, K. Varma and B. Mathur, "High Trans Fatty Acid Content in Common Indian Fast Foods," Nutrition \& Food Science, Vol. 38, No. 6, 2008, pp. 564569. http://dx.doi.org/10.1108/00346650810920178 
[6] S. A. McNaughton, C. S. Moore and S. P. Bryant, "Relationship between Dietary Intake of Essential Polyunsaturated Fatty Acids and Plasma Status in a Food-Based Intervention Study," Proceedings of the Nutrition Society, Vol. 63, 2004, p. 38A.

[7] K. S. Reddy, D. Prabhakaran, V. Chaturvedi, P. Jeemon, K. R. Thankappan, L. Ramakrishnan, B. V. M. Mohan, C. S. Pandav, S. U. Ahmed, P. P. Joshi, R. Meera, R. B. Amin, R. C. Ahuja, M. S. Das and T. M. Jaison (On Behalf of the Sentinel Surviellance System for Indian Industrial Populations Study Group), "Methods for Establishing a Surveillance System for Cardiovascular Diseases in Indian Industrial Populations," Bulletin of the World Health Organization, Vol. 84, No. 6, 2008, pp. 461-469. http://dx.doi.org/10.2471/BLT.05.027037

[8] "AOAC Fat (Total, Saturated and Unsaturated) in Foods, Hydrolytic Extraction Gas Chromatographic Method," 18th Edition, AOAC Official Method 996.06, AOAC International, Arlington, 2001.

[9] "AOAC Fatty Acid in Oils and Fats Preparation of Methyl Ester Boron Trifluoride Method," 15th Edition, AOAC Official Method 969.33, AOAC International, Washington DC, 1990.

[10] J. McCarthy, D. Barr and A. Sinclair, "Determination of Trans Fatty Acid Levels by FTIR in Processed Foods in Australia," Asia Pacific Journal of Clinical Nutrition, Vol. 17, No. 3, 2008, pp. 391-396.

[11] S. M. Innis and D. J. King, "Trans Fatty Acids in Human Milk Are Inversely Associated with Concentrations of Essential All-Cis n-6 and n-3 Fatty Acids and Determine Trans, but Not n-6 and n-3 Fatty Acids in Plasma Lipids of Breast-Fed Infants," American Journal of Clinical Nutrition, Vol. 70, No. 3, 1999, pp. 383-390.

[12] Z. Huang, B. Wang, R. D. Pace and J. H. Oh, "Trans Fatty Acid Content of Selected Foods in an African-American Community," Journal of Food Science, Vol. 71, No. 6, 2006, pp. C322-C327. http://dx.doi.org/10.1111/j.1750-3841.2006.00056.x
[13] E. Stachowska, K. Luterek, I. Gutowska, P. Zyluk, J. Bober and D. Chlubek, "Atherogenic Trans Isomers of Fatty Acids in Some Food Products," Annales Academiae Medicae Stetinensis, Vol. 52, No. 1, 2006, pp. 13-16.

[14] W. M. Ratnayake, R. Hollywood, E. O'Grady and G. Pelletier, "Fatty Acids in Some Common Food Items in Canada," Journal of the American College of Nutrition, Vol. 12, No. 6, 1993, pp. 651-660. http://dx.doi.org/10.1080/07315724.1993.10718356

[15] M. J. Albers, L. J. Harnack, L. M. Steffen and D. R. Jacobs, "Marketplace Survey of Trans-Fatty Acid Content of Margarines and Butter, Cookies and Snack Cakes and Savory Snacks," Journal of the American Dietetic Association, Vol. 108, No. 2, 2008, pp. 367-370. http://dx.doi.org/10.1016/j.jada.2007.10.045

[16] H. Fu, L. Yang, H. Yuan, P. Rao and Y. M. Lo, “Assessment of Trans Fatty Acids Content in Popular WesternStyle Products in China," Journal of Food Science, Vol. 73, No. 8, 2008, pp. s383-s391. http://dx.doi.org/10.1111/j.1750-3841.2008.00907.x

[17] S. Johnson, R. Sahu and P. Saxena, "Nutritional Analysis of Junk Food," Centre for Science and Environment, 2012 .

http://www.downtoearth.org.in/dte/userfiles/images/Nutri tional_Analysis_Junk_Food.pdf

[18] S. Alireza, C. P. Tan, Hamed and Y. B. Che Man, "Effect of Frying Process on Fatty Acid Composition and Iodine Value of Selected Vegetable Oils and Their Blends," International Food Research Journal, Vol. 17, No. 2, 2010, pp. 295-302.

[19] A. E. R. Soliman, A. Elmakhzangy and M. F. Ramadan, "Antiradical Performance and Physicochemical Characterisitics of Vegetable Oils upon Frying of French Fries: A Preliminary Comarative Study," Journal of Food Lipids, Vol. 13, No. 3, 2006, pp. 259-276. http://dx.doi.org/10.1111/j.1745-4522.2006.00050.x 